Journal of Applied Pharmaceutical Science Vol. 5 (11), pp. 050-054, November, 2015

Available online at http://www.japsonline.com

DOI: $10.7324 / \mathrm{JAPS} .2015 .501108$

ISSN 2231-3354 (cc) BY-NC-SA

\title{
Antifungal potential of the Seed and Leaf Foeniculum vulgare Mill essential Oil in liquid and vapor phase against phytopathogenic fungi
}

\author{
Sellam Khalid ${ }^{*}$, Bammou Mohamed ${ }^{1,2}$, Ramchoun Mhamed $^{3}$, Bouhlali Eimad Dine Tariq ${ }^{1}$, J'aiti Fatima ${ }^{4}$, Nassiri \\ Laila $^{2}$, El Rhaffari Lhoussaine ${ }^{1}$ \\ ${ }^{1}$ Environment and Health Laboratory, Faculty of Sciences \& Technology Errachidia, Morocco. \\ ${ }^{2}$ Soil Microbiology and Environment Laboratory, Faculty of Sciences Meknes, Morocco. \\ ${ }^{3}$ Biochemistry of Natural Products Laboratory, Faculty of Sciences \&Technology Errachidia, Morocco. \\ ${ }^{4}$ Laboratory of Protection, Improvement and Plant Ecophysiology, Faculty of Sciences \& Technology Errachidia, Morocco.
}

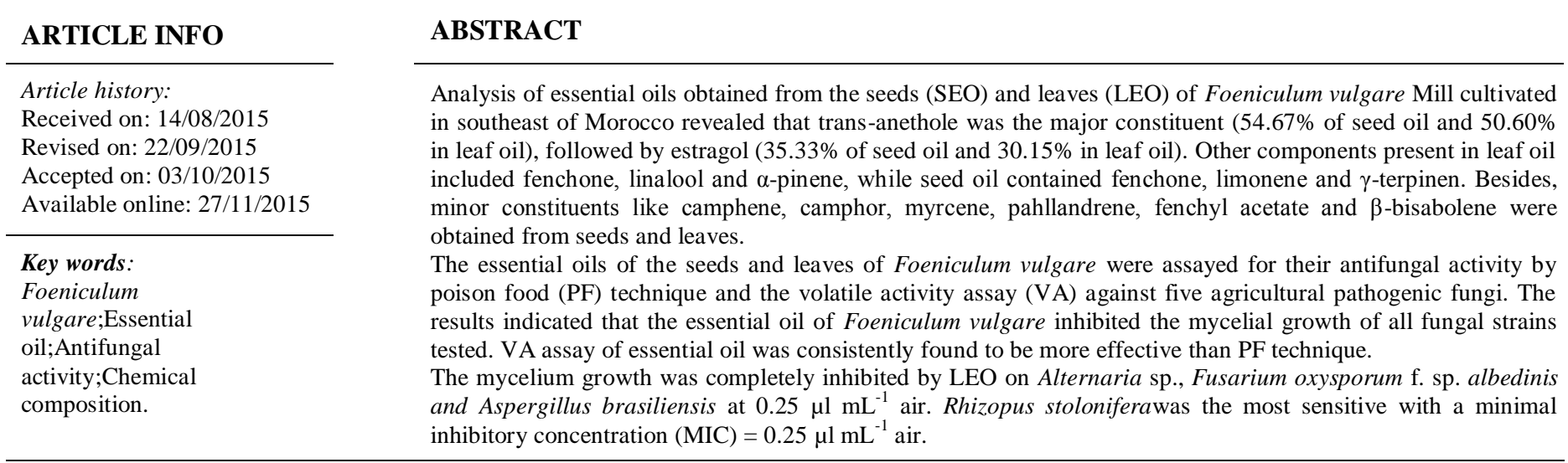

\section{INTRODUCTION}

Foeniculum vulgare Mill (Umbelliferaceae). Commonly known as fennel, is a small genus of annual, biennial or perennial herbs. It is widely cultivated for its aromatic fruits, which are used as culinary spices (Rather et al., 2012). Herbal drugs and essential oil of fennel has different pharmacological properties such as anti-spasmodic, anti-allergic, diuretic, antiinflammatory, analgesic and antioxidant effect (Ebeed et al., 2010, Choi and Hwang, 2004, Misharina and Polshkov, 2005, Parejo et al., 2002, Pradhan et al.,2008, Kooti et al., 2015). In addition, the volatile oil showed antimicrobial and

\footnotetext{
* Corresponding Author

Health and Environment Laboratory, Department of Biology, BP 509, Boutalamine, Faculty of Sciences \& Techniques, 52000 Errachidia, Morocco. Email: sellam.khalid2010@gmail.com
}

hepatoprotective (Sellam et al., 2014, Toma et al., 2008, Özbek et al., 2003), antithrombotic activity (Tognolini et al., 2007), antidiabetic activity (El-Soud et al., 2011), antitumour activity (Pradhan et al., 2008) and acaricidal activity (Lee, 2004).

In this study, the chemical compositions were studied by $\mathrm{GC} / \mathrm{SM}$ analysis and the antifungal activity was evaluated in vitro by poison food (PF) technique and the volatile activity assay (VA) against fives agricultural pathogenic fungi.

\section{MATERIAL AND METHODS}

\section{Plant material}

The seeds and leaves of Foeniculum vulgare were collected from Tafilalet (southeast of Morocco). The voucher specimens have been deposited at the Biochemistry of Natural Products Laboratory, Department of Biology, Faculty of Sciences $\&$ Techniques, Errachidia, Morocco. 


\section{Hydrodistillation apparatus and procedure}

The essential oils were obtained by hydrodistillation method from fresh leaves and seeds collected from the plants grown in the Errachidia region during juin 2013.

The yield of essential oil obtained from the seeds (SEO) and leaves (LEO) was found to be $2.8 \%$ and $2 \%$. The obtained essential oil was dried over anhydrous sodium sulfate and after filtration, stored at $+4^{\circ} \mathrm{C}$ until tested and analyzed.

\section{Essential oil analysis}

Components were identified on the basis of gas chromatography-mass spectrometry (GC-MS) library and confirmed by calculation of retention indices from GC-FID. GCMS was performed on a GC 6890 Agilent equipped with an HPINNOWAX capillary column $(50 \mathrm{~m} \times 0.2 \mathrm{~mm}$; film thickness 0.5 $\mu \mathrm{m})$. Carrier gas: Helium $1.6 \mathrm{ml} / \mathrm{min}$, split $1 / 100$; injector temperature: $280^{\circ} \mathrm{C}$; oven temperature: $60^{\circ} \mathrm{C}$ ( $2 \mathrm{~min}$ isothermal) then $3^{\circ} \mathrm{C} / \mathrm{min}$ to $180^{\circ} \mathrm{C}$, then $8^{\circ} \mathrm{C} / \mathrm{min}$ to $245^{\circ} \mathrm{C}(10 \mathrm{~min}$ isothermal). MS $5973 \mathrm{~N}$ Agilent; source temperature: $230^{\circ} \mathrm{C}$; mass range: 35 to $350 \mathrm{amu}$; scan speed: $1 \mathrm{scan} / \mathrm{sec}$. GC-FID: Fast GC HP- 6850 equipped with a DB-WAX capillary column $(20 \mathrm{~m}, 0.1$ $\mathrm{mm}, 0.2 \mu \mathrm{m}$ ). Carrier gas $\mathrm{H} 2$ at $0.7 \mathrm{ml} / \mathrm{min}$, split $60 \mathrm{ml} / \mathrm{min}$. Injector temperature $275^{\circ} \mathrm{C}$; Detector temperature $275^{\circ} \mathrm{C}$; oven temperature $60^{\circ} \mathrm{C}$ ( $2 \mathrm{~min}$ isothermal) then $12^{\circ} \mathrm{C} / \mathrm{min}$ to $248^{\circ} \mathrm{C}$ (5min isothermal). Detected compound concentrations are relative percentages (ISO7609), with a threshold of $0.05 \%$.

\section{Antifungal activity \\ Fungal strains}

Fives agricultural pathogenic fungi were selected for their implication in the contamination and the deterioration of the foodstuffs and production of mycotoxins. The fungal species used in the experiments are Alternaria sp, Pencillium expansum, Rhizopus stolonifer, Fusarium oxysporum f. sp. albedinisand Aspergillus brasiliensis ATCC 16404. These fungi are obtained from the culture collection at Faculty of Sciences \& Technology, Errachidia.

\section{Antifungal activity assay}

The antifungal activity of the SEO and LEO of Foeniculum vulgareagainst mycelial growth of fungi was tested following poisoned food technique (PF) (Perrucci et al., 1994) and volatile activity assay (VA) (Soylu et al., 2010) with some modifications.

\section{Poison food (PF) technique}

The essential oil was dispersed as an emulsion in sterile agar suspension (0.2\%) (Remmal et al., 1993) and added to PDA immediately before it was emptied into the glass Petri dishes $\left(90 \times 20 \mathrm{~mm}\right.$ in diameter) at a temperature of $40-45^{\circ} \mathrm{C}$.

The concentrations tested were 0.062 to $1 \mu 1 \mathrm{~mL}^{-1}$. The controls received the same quantity of sterile agar suspension $(0.2 \%)$ mixed with PDA. The tested fungi were inoculated with 6 $\mathrm{mm}$ mycelial plugs from 7-days-old cultures cut with a sterile cork and incubated for 3 days for Rhizopus stolonifer and 6 days for Alternaria sp, Pencillium expansum, Fusarium oxysporum f. sp. albedinisand Aspergillus brasiliensis at $25 \pm 2^{\circ} \mathrm{C}$.

\section{Volatile activity assay}

The Petri dishes were filled with $20 \mathrm{~mL}$ of potato dextrose agar (PDA) medium and then seeded with a mycelial disc (6 $\mathrm{mm}$ diameter), cut from the periphery of 7-days--old mycelium culture of the tested fungi. The Petri dishes $(90 \times 20 \mathrm{~mm}$, which offer $80 \mathrm{~mL}$ air spaces after addition of $20 \mathrm{~mL}$ agar media), were inverted and sterile filter paper discs $(9 \mathrm{~mm}$ in diameter $)$ impregnated with different concentrations of essential oil: 0.062 , $0.125,0.25,0.5$ and $1 \mu 1 \mathrm{~mL}^{-1}$ air are deposited on the inverted lid and incubated for 3 days for Rhizopus stolonifer and 6 days for Alternaria sp, Pencillium expansum, Fusarium oxysporum f. sp. albedinisand Aspergillus brasiliensis at $25 \pm 2^{\circ} \mathrm{C}$.

In both types of experiments, three replicate plates were inoculated for each treatment and the radial growth was recorded for each plate by calculating the average of two perpendicular diameters. Fungitoxicity of essential oil was expressed in terms of percentage of mycelial growth inhibition (I \%) and calculated following the formula of Pandey et al. (Pandey et al., 1982):

Percentage of mycelial growth inhibition $(\mathrm{IP})=\left(1-\left(\frac{\mathrm{Dc}}{\mathrm{Dt}}\right)\right) \times 100$ Where:

Dc: Average diameter (in $\mathrm{mm}$ ) of mycelial in control,

Dt: Average diameter (in $\mathrm{mm}$ ) of mycelial in treatment.

The fungistatic-fungicidal nature of essential oil was tested by observing revival of growth of the inhibited mycelial disc following its transfer to non-treated PDA. A fungicidal effect was where there was no growth, whereas a fungistatic effect was where temporary inhibition of microbial growth occurred.

\section{Statistical analysis}

Results are presented as mean \pm SD of three independent tests. All tests were carried out in an identical condition.

\section{RESULTS AND DISCUSSION}

\section{Chemical Composition of the Essential Oil}

The yellowish oils isolated by hydrodistillation from the leaves and the seeds of $F$. vulgare was obtained in a yield of $2 \%$ and $2.8 \%(\mathrm{w} / \mathrm{w})$ respectively. The essential oil was analyzed by means of GC-MS. The components of the oil, the retention times (RT) the percentage constituent (\%) are summarized in Table 1. The number of identified compounds was 24 in the seeds and 26 in the leaves, representing $97.05 \%$ and $98.16 \%$ of the total composition of the two organs.

Trans anethole $(50.60 \%)$, estragole $(30.15 \%)$, fenchone (4.32\%), linalool (2.83\%), $\alpha$-pinene $(2.56 \%)$ and $\gamma$-terpinene $(2.02 \%)$ were the main components for the leaf oil, comprising $92.48 \%$ of the oil. Trans anethole (54.67\%), estragole (35.33\%) and $\alpha$-pinene $(2.01 \%)$ were the main components for the seed oil, comprising $92.01 \%$ of the oil. 
The components present in the essential oil obtained from seeds and leaves of fennel cultivated Tafilalet region are similar to those reported for sweet fennel but the relative percentage of compounds such as anethole, estragole and fenchone differed (Chowdhury et al., 2009, Ebeed et al., 2010, Raal et al., 2012, Fratini et al., 2014, Diao et al., 2014). It may be attributed to different factors such as geographical environment, growth season and physiological age of the plant besides the method of oil isolation (Díaz-Maroto et al., 2005).

Table 1: Essential oil Composition of Foeniculum vulgare Mill cultivated in southeast of Morocco.

\begin{tabular}{cccc}
\hline $\mathbf{R t}^{\mathbf{a}}$ & Compounds $^{\mathbf{b}}$ & Leaf oil (LEO) & Seed oil (SEO) \\
\hline 4,08 & $\alpha$-thujone & 0.21 & 0.21 \\
$\mathbf{8 , 4 9}$ & a-pinene & $\mathbf{2 . 5 6}$ & $\mathbf{2 . 0 1}$ \\
9,95 & camphene & 0.2 & 0.32 \\
10,56 & sabinene & 0.29 & 0.29 \\
10,95 & $\beta$-pinene & 0.3 & - \\
11,68 & mycerene & 0.03 & 0.06 \\
11,82 & $\Delta$-3-carene & 0.61 & 0.61 \\
12,25 & $\alpha$-terpinene & 0.4 & 0.06 \\
12,92 & p-cymene & 0.22 & 0.23 \\
$\mathbf{1 3 , 0 4}$ & limonene & $\mathbf{1 . 2}$ & $\mathbf{0 . 4}$ \\
$\mathbf{1 3 , 8 4}$ & $\boldsymbol{\gamma}$-terpinene & $\mathbf{2 . 0 2}$ & $\mathbf{1 . 2}$ \\
$\mathbf{1 3 , 9 5}$ & fenchone & $\mathbf{4 . 3 2}$ & $\mathbf{0 . 0 6}$ \\
$\mathbf{1 4 , 4 6}$ & linalool & $\mathbf{2 . 8 3}$ & $\mathbf{1 . 0 9}$ \\
15,9 & camphor & 0.27 & 0.98 \\
16,04 & terpinen-4-ol & 0.3 & 0.03 \\
16,84 & methyl chavicol & 0.02 & 0.27 \\
17,15 & fenchyl acetate & 0.13 & 0.03 \\
$\mathbf{1 8 , 0 1}$ & estragole & $\mathbf{3 0 . 1 5}$ & $\mathbf{3 5 . 3 3}$ \\
$\mathbf{2 1 , 0 5}$ & trans anethole & $\mathbf{5 0 . 6}$ & $\mathbf{5 4 . 6 7}$ \\
23,83 & thymol & 0.02 & 0.03 \\
24,81 & $\alpha$-copaene & 0.21 & 0.05 \\
27,09 & $\beta$-caryophyllene & 0.06 & 0.16 \\
27,71 & $\alpha$-phellandrene & 0.07 & - \\
28,36 & $\beta$-bisabolene & 0.03 & 0.07 \\
& Total & $\mathbf{9 7 . 0 5 \%}$ & $\mathbf{9 8 . 1 6 \%}$ \\
\hline
\end{tabular}

${ }^{a}$ Compounds listed in order of elution.

${ }^{\mathrm{b}}$ Retention time (as minutes).

\section{Antifungal activity}

The antifungal activity was obtained using the PF technique with different concentrations of SEO and LEO of Foeniculum vulgare is reported in Figures 1 and 2, respectively.
The results (Fig.1) showed that Alternaria $s p$. and $F$. oxysporumalbedinis, was found to be The fungal susceptible to the LEO of Foeniculum vulgare followed by $P$. expansum with the percentages of inhibition (IP) are $100 \pm 0.00 \%$ and $81.00 \pm 2.42 \%$ at $1 \mu 1 \mathrm{~mL}^{-1}$, respectively. Conversely, A. brasiliensis had a high resistance to this essential oil with IP equal to $70.80 \pm 0.67$ at $1 \mu \mathrm{l}$ $\mathrm{mL}^{-1}$. The IP against Alternaria sp., $P$. expansum and F. Oxysporumobedience were moderates (more than $30 \%$ ) at $0.0625 \mu \mathrm{lmL} \mathrm{m}^{-1}$.

The results (Fig.2) showed that the SEO of Foeniculum vulgare is less active against fives phytopathogens tested. The IP were moderately at $0.25 \mu \mathrm{mL}^{-1}$ (ranged from $22.09 \pm 1.16 \%$ to $43.82 \pm 1.17 \%$ ) and relatively effective at $1 \mu 1 \mathrm{~mL}^{-1}$. The IP was low at small concentrations $\left(0.0625 \mu \mathrm{l} \mathrm{mL} \mathrm{mL}^{-1}\right)(13.90 \pm 2.32 \%$ for Alternaria sp and $03.10 \pm 0.67 \%$ for $A$. brasiliensis).

Table 2: Minimal inhibitory concentration (MIC) and minimal fungicidal concentration (MFC) values in $\mu 1 / \mathrm{mL}$ air

\begin{tabular}{lcccc}
\hline & \multicolumn{2}{c}{ SEO } & \multicolumn{2}{c}{ LEO } \\
\hline Strains & MIC & MFC & MIC & MFC \\
\hline Alternaria sp. & 0.25 & 1 & 0.25 & 0.5 \\
P. expansum & 0.5 & 1 & 0.5 & 1 \\
F. oxysporumalbedinis & 0.5 & 1 & 0.25 & 0.5 \\
A. brasiliensis (ATCC 16404) & 0.5 & 1 & 0.25 & 0.5 \\
R. stolonifer & 0.5 & 1 & 0.125 & 0.5 \\
\hline
\end{tabular}

Using VA assay, the results showed that the activity of the vapor of the Foeniculum vulgare essential oil was more pronounced for all strains tested (Figures3 and 4). The mycelium growth was totally inhibited $(100 \pm 0.00 \%)$ at $0.25 \mu 1 \mathrm{~mL}^{-1}$ air by LEO for Alternaria sp., A. brasiliensis and $F$. oxysporum albedinis. Moreover, the mycelium growth of $P$. Expansum and was only partially inhibited at the same concentration for LEO. Conversely, $R$. stolonifer had a high sensitivity to the LEO with the CMI was $1.125 \mu 1 \mathrm{~mL}^{-1}$ air.

It is interesting to know the fungitoxic nature of this vapor oil against all fungal strains tested. Indeed, the transfer of mycelial discs where growth inhibition was complete by Foeniculum vulgare vapor into the PDA medium without this oil.

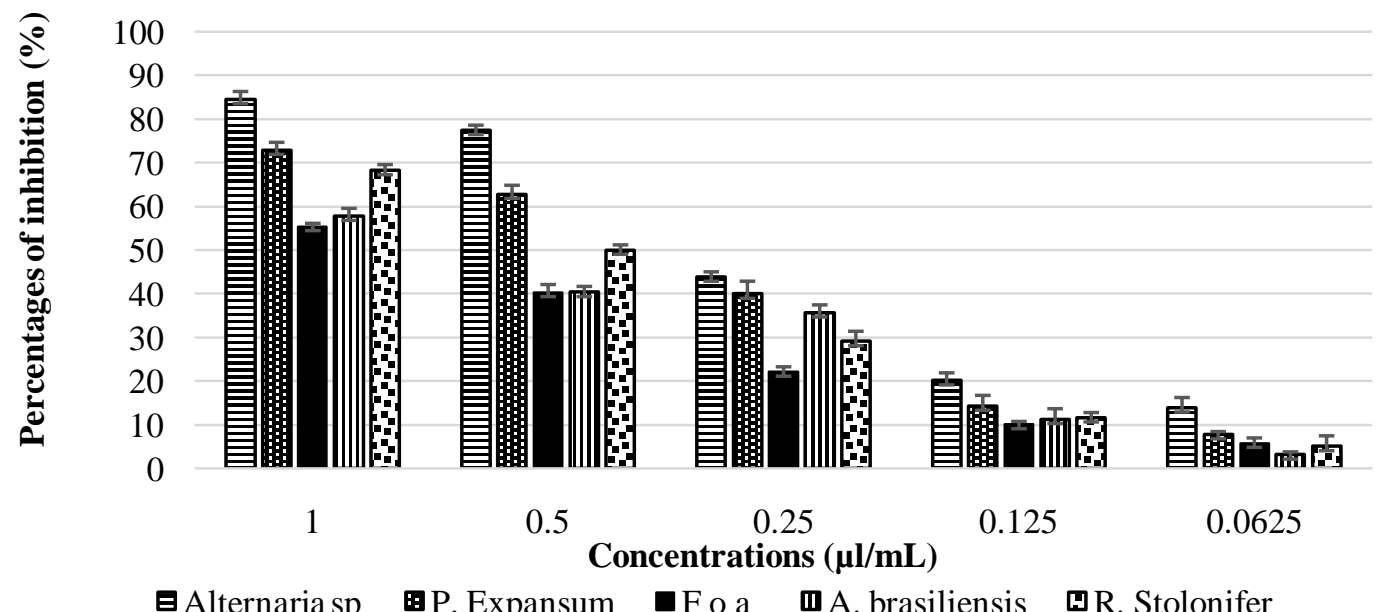

Fig. 1: The effect of different concentrations of Foeniculum vulgareSEO using a PF technique against the mycelial growth. 


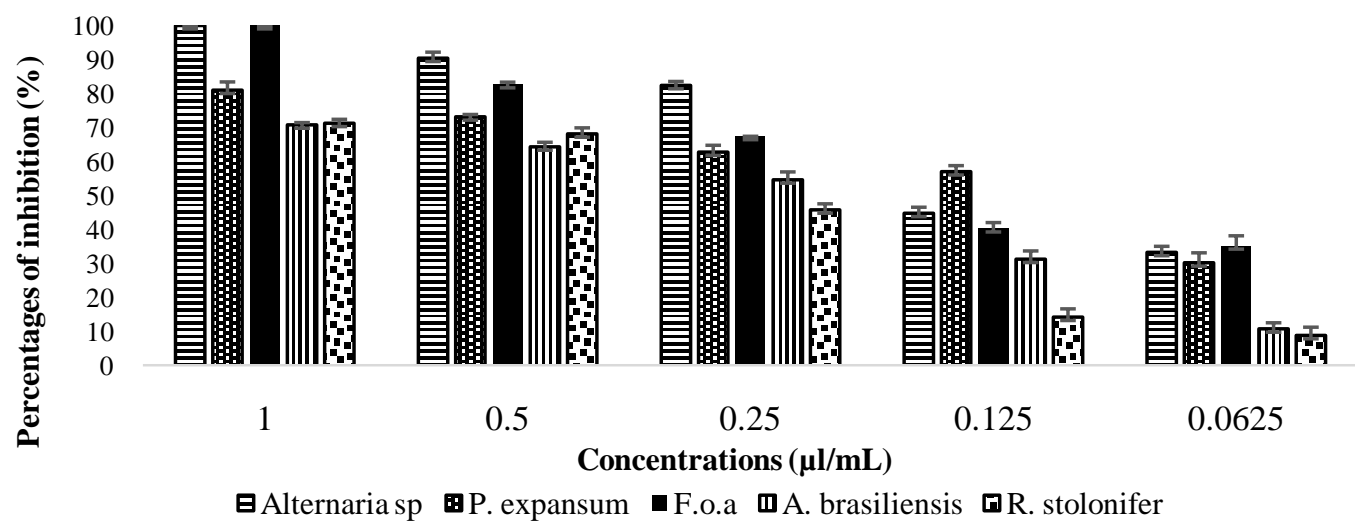

Fig. 2: The effect of different concentrations of Foeniculum vulgareLEO using a PF technique against the mycelial growth.

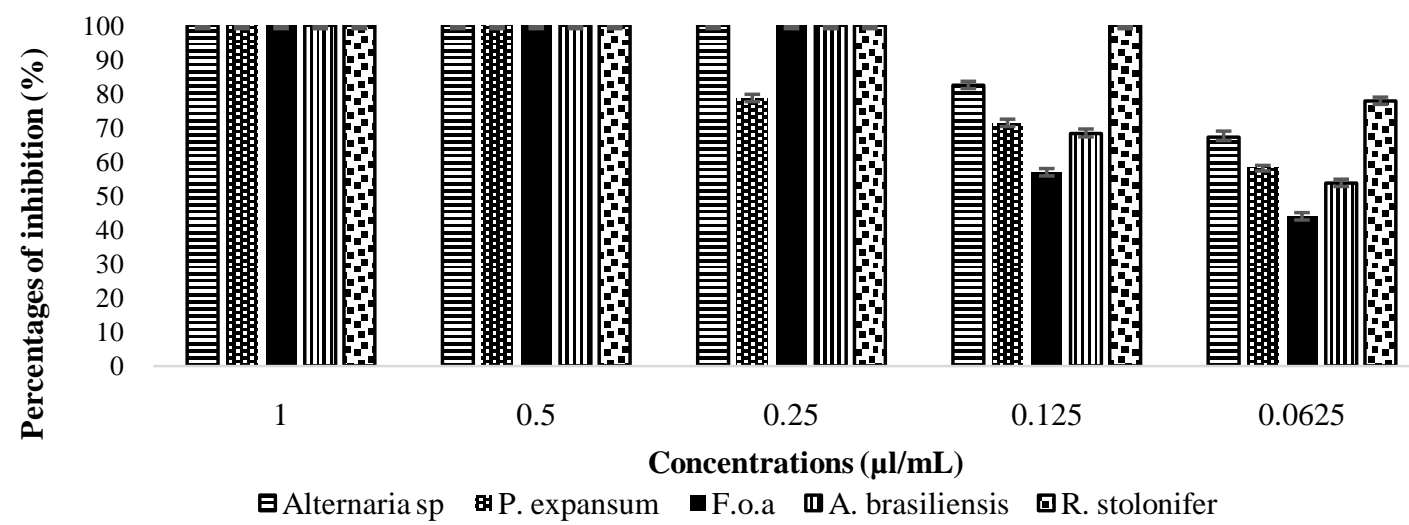

Fig. 3: The effect of different concentrations of Foeniculum vulgareLEO using a VA assay against the mycelia.

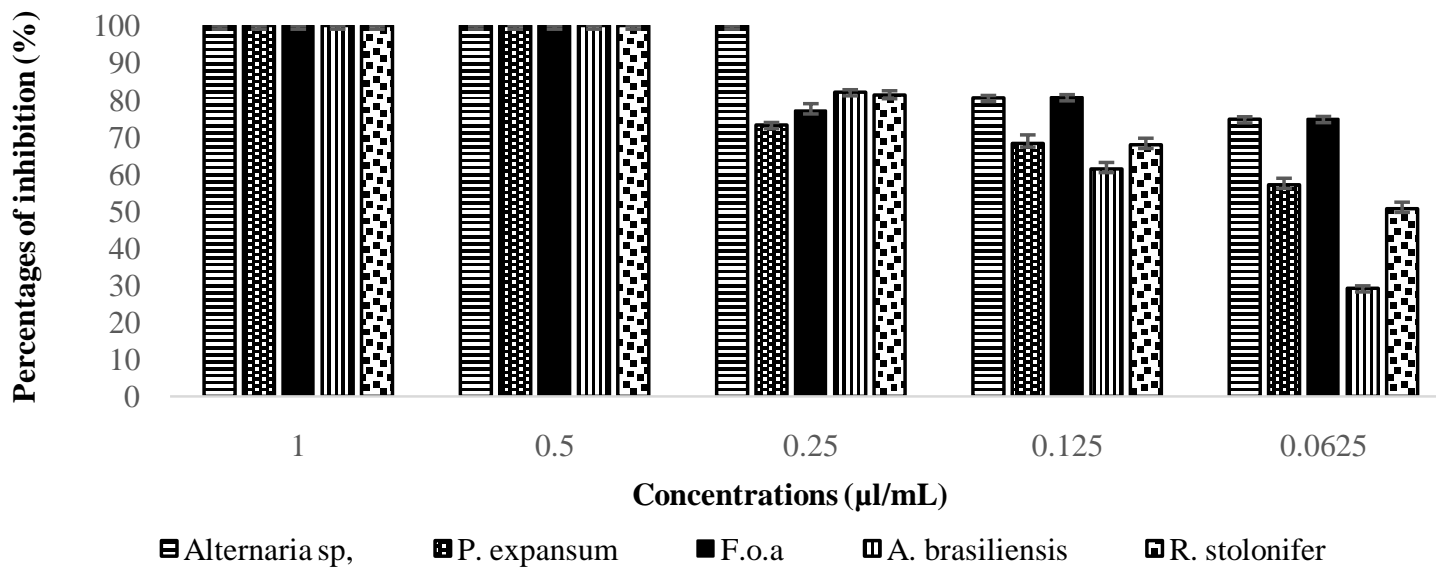

Fig. 4: The effect of different concentrations of Foeniculum vulgareSEO using a VA assay against the mycelia.

The results (Table 2) showed no growth over an incubation period, suggesting the fungicidal effect of the LEO on all strains tested at $0.5 \mu 1 \mathrm{~mL}^{-1}$ air, except $P$. expansum with the MFC was $1 \mu \mathrm{l} \mathrm{mL} L^{-1}$ air. On the contrary, at same concentration the mycelial growth after some days of incubation was observed, indicating a fungistatic effect for SEO on all strains. The antifungal activity of Foeniculum vulgare is probably related to the high content of trans anethole $(50.6 \%$ from LEO and $54.67 \%$ from SEO). The importance of this compound was demonstrated by (Singh et al., 2006) which reported that trans-anethole had strong antifungal activity against various fungi. According to the results obtained in this study, vapor from Foeniculum vulgare oil has better antifungal activity against the pathogens tested than that observed in the PF technique. Previous antifungal studies have indicated that VA assay is more effective than the PF method. The volatile fractions of Rosmarinus officinalis and Eucalyptus globulus strongly inhibited the mycelial growth of all fungi tested (Survilienè et al., 2009).A vapor activity assay of Citrus sinensis 
essential oil showed that the oil was fungicidal for Penicillium expansum, Ulocladium chartarum and Alternaria mali from apples (Sharma and Tripathi, 2006).

\section{CONCLUSIONS}

Concluding these results, we can say that $F$. vulgare volatile oil, which is rich in trans-anethole $(54.67 \%$ in seed oil and $50.60 \%$ in leaf oil) and estragol (35.33\% in seed oil and $30.15 \%$ in leaf oil), possesses good antifungal activity against Alternaria sp, Pencillium expansum, Rhizopus stolonifer, Fusarium oxysporum $\mathrm{f}$. sp. albedinisand Aspergillus brasiliensis ATCC 16404.

The use of $F$. vulgare oil in vapor phase may be considered as a potential alternative to synthetic fungicides for the phytopathogenic fungi. A further study in vivo condition is warranted to confirm the antifungal activity of $F$. vulgare oil, which may be used for preservation and/or extend the shelf life of raw and processed food.

\section{REFERENCES}

Choi EM and Hwang JK. Antiinflammatory, analgesic and antioxidant activities of the fruit of Foeniculum vulgare, Fitoterapia, 2004; 75(6): 557-565.

Chowdhury JU, Mobarok MH, Bhuiyan MNI and Nandi NC. Constituents of essential oils from leaves and seeds of Foeniculum vulgare Mill. cultivated in Bangladesh, Bangladesh J. Bot., 2009; 38(2): 181-183.

Diao WR, Hu QP, Zhang H and Xu JG. Chemical composition, antibacterial activity and mechanism of action of essential oil from seeds of fennel (Foeniculum vulgare Mill.). Food Control, 2014; 35(1): 109-116.

Díaz-Maroto MC, Díaz-Maroto Hidalgo IJ, Sánchez-Palomo E and Pérez-Coello MS. Volatile components and key odorants of fennel (Foeniculum vulgare Mill.) and thyme (Thymus vulgaris L.) oil extracts obtained by simultaneous distillation-extraction and supercritical fluid extraction. J. Agric. Food Chem., 2005; 53(13): 5385-5389.

Ebeed NM, Abdou HS, Booles HF, Salah SH, Ahmed ES and Fahmy K. Antimutagenic and chemoprevention potentialities of sweet fennel (Foeniculum vulgare Mill.) hot water crude extract. J Am Sci, 2010; 6(9): 831-842.

El-Soud NA, El-Laithy N, El-Saeed G, Wahby MS, Khalil M, Morsy F and Shaffie N. Antidiabetic activities of Foeniculum vulgare Mill. essential oil in streptozotocin-induced diabetic rats. Maced. J. Med. Sci., 2011; 4(2): 139-146.

Fratini F, Casella S, Leonardi M, Pisseri F, Ebani VV, Pistelli L and Pistelli L. Antibacterial activity of essential oils, their blends and mixtures of their main constituents against some strains supporting livestock mastitis. Fitoterapia, 2014; 96: 1-7.

Kooti W, Moradi M, Akbari SA, Sharafi-Ahvazi N, AsadiSamani M and Ashtary-Larky D. Therapeutic and pharmacological potential of Foeniculum vulgare Mill: a review. J. HerbMed Pharmacol., 2015; 4(1): 1-9.

Lee HS. Acaricidal activity of constituents identified in Foeniculum vulgare fruit oil against Dermatophagoides spp.(Acari: Pyroglyphidae). J. Agric. Food Chem., 2004; 52(10): 2887-2889.

Misharina $\mathrm{T}$ and Polshkov A. Antioxidant properties of essential oils: autoxidation of essential oils from laurel and fennel and of their mixtures with essential oil from coriander. Appl. Biochem. Microbiol., 2005; 41(6): 610-618.

Pandey D, Tripathi N, Tripathi R and Dixit S. Fungitoxic and phytotoxic properties of the essential oil of Hyptis suaveolens. Zeitschrift für Pflanzenkrankheiten und Pflanzenschutz, 1982; 89: 344-349.
Parejo I, Viladomat F, Bastida J, Rosas-Romero A, Flerlage N, Burillo $\mathrm{J}$ and Codina $\mathrm{C}$. Comparison between the radical scavenging activity and antioxidant activity of six distilled and nondistilled Mediterranean herbs and aromatic plants. J. Agric. Food Chem., 2002; 50(23): 6882-6890.

Perrucci S, Mancianti F, Cioni P, Flamini G, Morelli I and Macchioni G. In vitro antifungal activity of essential oils against some isolates of Microsporum canis and Microsporum gypseum. Planta med., 1994; 60(2): 184.

Pradhan M, Sribhuwaneswari S, Karthikeyan D, Minz S, Sure P, Chandu AN, Mishra U, Kamalakannan K, Saravanankumar A and Sivakumar T. In-vitro cytoprotection activity of Foeniculum vulgare and Helicteres isora in cultured human blood lymphocytes and antitumour activity against B16F10 melanoma cell line.Res. J. Pharm. Technol., 2008; 1(4): 450-452.

Raal A, Orav A and Arak E. Essential oil composition of Foeniculum vulgare Mill. fruits from pharmacies in different countries. Nat. Prod. Res., 2012; 26(13): 1173-1178.

Rather MA, Dar BA, Sofi SN, Bhat BAand Qurishi MA. Foeniculum vulgare: A comprehensive review of its traditional use, phytochemistry, pharmacology, and safety.Arabian J. Chem., 2012. in Press: doi:10.1016/j.arabjc.2012.04.011

Remmal A, Bouchikhi T, Rhayour K, Ettayebi M and TantaouiElaraki A. Improved method for the determination of antimicrobial activity of essential oils in agar medium.J. Essent. Oil Res., 1993; 5(2): 179-184.

Sellam K, Ramchoun M, Bammou M, Alem C and El Rhaffari L. Chemical Composition and Bioactivity of Essential Oils of Seed and Leaf from Foeniculum vulgare Mill cultivated in Southeast of Morocco. Journal of Natural Sciences Research, 2014; 4(17): 33-38.

Sharma N and Tripathi A. Fungitoxicity of the essential oil of Citrus sinensis on post-harvest pathogens. World Journal of Microbiology and Biotechnology, 2006; 22(6): 587-593.

Singh G, Maurya S, De Lampasona M and Catalan C. Chemical constituents, antifungal and antioxidative potential of Foeniculum vulgare volatile oil and its acetone extract. Food control, 2006; 17(9): 745-752.

Soylu EM, Kurt Ş and Soylu S. In vitro and in vivo antifungal activities of the essential oils of various plants against tomato grey mould disease agent Botrytis cinerea.Int. J. Food Microbiol, 2010; 143(3): 183189.

Survilienė E. Valiuškaitė A, Snieškienė V and Stankevičienė A. Effect of essential oils on fungi isolated from apples and vegetables. Sodininkystė ir Daržininkystė, 2009; 28(3): 227-234.

Tognolini M, Ballabeni V, Bertoni S, Bruni R, Impicciatore M and Barocelli E. Protective effect of Foeniculum vulgareessential oil and anethole in an experimental model of thrombosis. Pharmacol. Res., 2007; 56(3): 254-260.

Toma C, Pancan I, Chirita M and Zamfir A. Electrospray ionization tandem mass spectrometric investigation of Melissa officinalis oil. Farmacia-Bucuresti, 2008; 56(1): 92.

Özbek H, Uğraș S, Dülger H, Bayram I, Tuncer I, Öztürk G and Öztürk A. Hepatoprotective effect ofFoeniculum vulgare essential oil. Fitoterapia, 2003; 74(3): 317-319.

\section{How to cite this article:}

Sellam Khalid, Bammou Mohamed, Ramchoun Mhamed, Bouhlali Eimad Dine Tariq, J'aiti Fatima, Nassiri Laila, El Rhaffari Lhoussaine. Antifungal potential of the Seed and Leaf Foeniculum vulgare Mill essential Oil in liquid and vapor phase against phytopathogenic fungi. J App Pharm Sci, 2015; 5 (11): 050-054. 